\title{
Natural Rubber Composites Filled with Cereals Straw Modified with Acetic and Maleic Anhydride: Preparation and Properties
}

\author{
Marcin Masłowski ${ }^{1}$ D Justyna Miedzianowska ${ }^{1} \cdot$ Krzysztof Strzelec $^{1}$
}

Published online: 30 July 2018

(c) The Author(s) 2018

\begin{abstract}
This research paper aims to provide an examinations on biocomposites based on natural rubber (NR), natural straw fibers as well as their production techniques and properties. After pre-alkalization of the fillers, two main modification methods were carried out, with the usage of acetic or maleic anhydride to improve the adhesion of the fibers to the elastomeric matrix. Firstly, physicochemical characterization of straw particles, both pure and modified, using scanning electron microscopy (SEM), thermogravimetric analysis (TGA) and Fourier transmission infrared spectroscopy (FTIR) was performed. Moreover full characterization of the produced composites was also executed, which included: rheogical properties, static and dynamic mechanical properties, crosslinking density, damping properties, tear strength and resistance to simulated aging processes. Increased adhesion between modified straw fibers and the elastomeric matrix was observed for $10 \mathrm{phr}$ filled composites, which was confirmed by dynamic mechanical thermal analysis (DMTA). In addition, the impact of the applied modifications was confirmed by higher values of the Payne effect, which resulted from the presence of developed secondary structure of the filler in vulcanizates. Furthermore, the crosslinking density of composites increased, which was reflected in the improvement of tensile properties, determined by tensile and tear strength and relative damping.
\end{abstract}

Keywords Natural rubber $\cdot$ Fillers $\cdot$ Biocomposites $\cdot$ Cereals straw modified $\cdot$ Elastomers

\section{Introduction}

Natural adhesion at the interface between the polymer matrix and fibers is one of the most important factor affecting the mechanical properties of fiber-reinforced composite materials [1]. The hydrophilic nature of natural fibers is provided by highly polarized hydroxyl groups derived from lignocellulose [2]. In the case of plant-based fibrous composites there is usually a limited interaction between hydrophilic fibers and matrices that are usually hydrophobic. This results in poor interfacial bonding, limiting resistance to moisture as well as mechanical performance, which consequently affects the long-term properties [3]. Achieving a homogeneous dispersion of fillers in polymers is extremely difficult due to their high surface energy. In order to improve the dispersion of the particles, the surface characteristics of the cellulose must be changed from hydrophilic to more hydrophobic

Marcin Masłowski

marcin.maslowski@p.lodz.pl

1 Institute of Polymer \& Dye Technology, Lodz University of Technology, Stefanowskiego 12/16, 90-924 Lodz, Poland
[4]. Wettability can be considered as a necessary bonding precursor, therefore the fiber and matrix must be brought into close contact for bonding to occur. On the other hand, insufficient wetting of fibers results in interfacial defects that act as stress concentrators [5]. Undoubtedly, wettability of fibers affects the toughness, tensile and flexural strength of composites, which has been confirmed in numerous literature reports $[3,6]$. The improvement in dispersing of highly polar cellulose in polymers is one of the main challenges to overcome due to the fact that cellulose presents great potential as a multifunctional natural filler [4].

The use of modifications of natural fibers, which can be made by chemical or physical methods, can reduce the hydrophilic nature of lignocellulosic fillers, and then improve the adhesion at the interface [1]. Literature reports give examples of applications of various physical modification methods such as corona discharge [7, 8], cold plasma treatment [9] and thermal treatment [10]. Notwithstanding, chemical approaches are more represented than physical with better improvements obtained to date. Chemical treatments include among others alkali, acetyl, silane, benzyl, acryl, permanganate, peroxide, isocyanate, 
titanate, zirconate and acrylonitrile treatments and use of maleated anhydride grafted coupling agent [11-15].

One of the most commonly used chemical treatments of natural fibers used to reinforce thermoplastics and thermosets is the alkaline treatment or mercerization [16]. During the mercerization process, cementing substances, such as waxes, lignin and hemicellulose are removed by affecting the chemical composition of flax fibers, the degree of polymerization and the molecular orientation of cellulose crystallites [17, 18]. As a result of alkalization, the cellulose fiber swells and the natural crystalline structure of the cellulose relaxes. Native cellulose which exhibits a monoclinic crystalline lattice of cellulose-I, can be changed into various polymorphic forms, i.e. alkaline cellulose and cellulose II [2]. The research results [19-24] show that the treatment of natural fibers with alkalis resulted in improved interfacial strength (IFSS) and improved tensile strength, Young's modulus, strength deformation, impact resistance, fracture toughness and bending properties of composites, as well as thermal stability and long-term resistance to moisture.

Acetylation is an esterification process where the polymeric hydroxyl groups of the cell wall of natural fibers react with acetyl groups and modify the properties of the polymer. Acetylation causes the plasticization of cellulose fibers, which become more hydrophobic, stabilizing the cell wall against moisture, improving dimensional stability and environmental degradation [25]. As a result of the modification acetic anhydride reacts with more reactive hydroxyl groups $(\mathrm{OH})$ in amorphous lignin and hemicellulose. At the same time, the hydroxyl groups of the crystalline cellulose prevent diffusion of the reagent and cause a low degree of reaction [26]. The literature reports that acetylation reduces the absorption of moisture from natural fibers and further enhances the interface of lignocellulosic material/polymer composites [27, 28]. Moreover, it was found that due to better thermal stability of the treated fibers and improved interaction between the fibers and the matrix, thermal stability of modified fiber composite is higher than the untreated fibrous composite material [29]. Furthermore, it was also reported that composites with acetylated fibers are characterized by significant biological resistance [30].

Anhydrous treatment consists of immersing the fibers in a solution of maleic anhydride in toluene or xylene in order to impregnate and react with hydroxyl groups on the fiber surface [17]. Modification with maleic anhydride (MA) is usually carried out to ensure compatibility between the matrix and the coupling agent and thus improve the properties of the specific composites materials [3]. It has been shown that MA can be used as an additive during processing or grafting to the fiber before processing which improves the tensile and bending strength as well as stiffness and impact strength of composites [31]. Literature reports that maleated coupling agents are widely used to strengthen composites containing fillers and fiber reinforcements [32-34].

Agricultural crop residues, represent an important resources, with a great potential as raw materials for polymers composites. Because of the enormous quantity of straw, its utilization to the utmost extent is now demanding attention in the major cereal-growing areas of the world. Up to date, only a few research papers have been published to improve and verify the physical, mechanical, barrier and damping properties of bioelastomer composites with the addition of straw [35-37]. Generally, researchers focus their interests mainly on thermoplastic polymers containing cereal or plant straw as a filler. Unfortunately, the problem of utilization of straw is still not fully resolved and requires search for new opportunities and technologies of its use.

This article is a continuation of our research on the influence of lignocellulosic fillers obtained from cereal straw on the properties of natural rubber composites. The objective of presented works was to investigate the influence of acetic and maleinic anhydrate modification on the properties of natural fibers (thermal stability, morphology and structure). Moreover detailed investigation has been carried out on the effect of modified fillers on the elastomer vulcanizates properties. Examinations of the fibre-matrix interface or the interfacial adhesion of the fibre and matrix are of utmost importance to the mechanical properties of composite materials. The applied modifications were aimed at improving both static and dynamic mechanical properties and utility properties (damping, tear strength, susceptibility to aging) of composites. This work is a innovative technological solution, which is designed to recognize and improve the opportunity to create composites with high application level, associated with a significant change in multifunctional properties.

\section{Experimental}

\section{Materials}

Details of the components used in this study are presented in Table 1.

The straw used in this study was cut to achieve the fibers with mean length of $4 \mathrm{~mm}$. In order to obtain a fine powder, the straw was milled using a ball mill. Next, the material was dried at $70{ }^{\circ} \mathrm{C}$. This straw was a pure (raw) straw.

For pre-alkali treatment, the powder of straw was soaked in an aqueous solution of sodium hydroxide (5 wt $\%$ ) for $2 \mathrm{~h}$ at $25{ }^{\circ} \mathrm{C}$. The straw was filtered off under reduced pressure, rinsed with water until neutral $\mathrm{pH}$ and dried to a constant mass at $70{ }^{\circ} \mathrm{C}$. Alkalized straw were treated with acetic anhydride solution $(5 \mathrm{wt} \%)$ in toluene for $2 \mathrm{~h}$ at $70{ }^{\circ} \mathrm{C}$. The acetylated straw was drained and washed several times with fresh water $(\mathrm{pH} \sim 7)$. Finally, the material was dried in an 
Table 1 Characteristics of components

\begin{tabular}{lll}
\hline Materials & Details and properties & Producer \\
\hline Natural rubber (NR) & cis-1,4-polyisoprene; density 0.93-0.98 $\mathrm{g} \mathrm{cm}^{-3}$ & Torimex Chemicals, Poland \\
Pure straw (S) & Wheat, rye, oat, triticale, barley straw & Local Polish farms \\
Acetic anhydride modified straw (AAS) & Straw was modified with $5 \%$ acetic anhydride in toluene & Lodz University of Technology \\
& for 120 min at $70{ }^{\circ} \mathrm{C}$ & Lodz University of Technology \\
Maleic anhydride modified straw (MAS) & Straw was modified with $10 \%$ maleic anhydride in & \\
& acetone for 120 min at $60{ }^{\circ} \mathrm{C}$ & Siarkopol, Poland \\
Sulfur $\left(\mathrm{S}_{8}\right)$ & Rhombic sulfur & Huta Bedzin, Bedzin, Poland \\
& Melting point: $112.8{ }^{\circ} \mathrm{C}$ & Dolnoslaskie Zakłady Chemiczne \\
Zinc oxide (ZnO) & BET surface area: $4-6 \mathrm{~m}^{2} \mathrm{~g}^{-1}$ & Organika, Poland \\
2-Mercaptobenzothiazole (MBT) & Density: $1.42 \mathrm{~g} \mathrm{~cm}{ }^{-3}$ & Avantor Performance Materials \\
& Melting point: $180-183{ }^{\circ} \mathrm{C}$ & Poland, Poland \\
\hline
\end{tabular}

air oven at $70{ }^{\circ} \mathrm{C}$ until completely dry. Maleic anhydride treatment was performed in the same way as the acetylation, but a solution of $10 \mathrm{wt} \%$ maleic anhydride in acetone at temperature $60{ }^{\circ} \mathrm{C}$ was applied. Chemical modification of lignocellulose by reaction with anhydrides was given in Fig. 1 [38].

The compositions of the studied rubber mixtures are presented in Table 2. The elastomers mixtures were prepared on Brabender measuring mixer N50 and laboratory two-roll mill following two-step procedure. First, the natural rubber and fillers were compounded by using mixer at $50{ }^{\circ} \mathrm{C}$. The mixing time included 4 min of mastication of natural rubber and 4 min of mixing NR with the biofillers. Next, the blend was mixed with the sulfur curing system on two-roll mill at a lower temperature (room temperature). After the mixing process, the uncured NR rubber mixtures were sheeted.

\section{Methods}

Thermogravimetric analysis of the dried straw was performed using the TGA/DSC1 (Mettler Toledo) analyzer. The thermograms were recorded between 25 and $600{ }^{\circ} \mathrm{C}$ with a heating rate of $10{ }^{\circ} \mathrm{C} \mathrm{min}^{-3}$ in a flow of nitrogen at $60 \mathrm{ml} \mathrm{min}{ }^{-1}$.

The FTIR Nicolet 6700 reflection ATR technique on an adapter with a diamond crystals on ZnSe plate was used to obtain the FTIR spectra. The FTIR spectra of straw were recorded at a resolution of $8 \mathrm{~cm}^{-1}$, with 128 scans, over the range of 4000-400 $\mathrm{cm}^{-1}$.

Vulcanization characteristics of the rubber mixtures were studied at $160{ }^{\circ} \mathrm{C}$ using an MonTech DRPA 300 Rheometer following ISO 3417 standard. The maximum torque $\left(\mathrm{M}_{\max }\right)$, minimum Torque $\left(\mathrm{M}_{\min }\right)$, curing time $\left(\mathrm{t}_{90}\right)$ and scorch time
Fig. 1 Chemical modification of lignocellulose by reaction with anhydrides'<smiles>[R]C(=O)OCC([Y])(C)OC([R])=O</smiles><smiles>[R]C(=O)OC(C)=O</smiles> 
Table 2 The compositions of biocomposites and reference sample

\begin{tabular}{|c|c|c|c|c|c|c|}
\hline & Straw (phr) & $\mathrm{NR}(\mathrm{phr})$ & SA (phr) & $\mathrm{ZnO}(\mathrm{phr})$ & MBT (phr) & Sulfur (phr) \\
\hline Ref. sample (NR) & 0 & 100 & 1 & 5 & 2 & 2 \\
\hline Pure untreated straw & $\begin{array}{l}10 \\
20 \\
30\end{array}$ & 100 & 1 & 5 & 2 & 2 \\
\hline Acetic anhydride modified straw & $\begin{array}{l}10 \\
20 \\
30\end{array}$ & 100 & 1 & 5 & 2 & 2 \\
\hline Maleic anhydride modified straw & $\begin{array}{l}10 \\
20 \\
30\end{array}$ & 100 & 1 & 5 & 2 & 2 \\
\hline
\end{tabular}

phr parts per houndred parts of rubber

$\left(t_{\mathrm{s} 2}\right)$ were given and/or calculated from the torque plot versus time.

Vulcanization of the blends was performed in a mold at $160{ }^{\circ} \mathrm{C}$ and $15 \mathrm{MPa}$ for time determined from rheometric measurements.

The crosslinking density of the vulcanized network was calculated on the basis of solvent-swelling measurements (in toluene) from the Flory-Rehner [39] Eq. (1).

$\gamma_{\mathrm{e}}=\frac{\ln \left(1-\mathrm{V}_{\mathrm{r}}\right)+\mathrm{V}_{\mathrm{r}}+\mu \mathrm{V}_{E}^{2}}{\mathrm{~V}_{0}\left(\mathrm{~V}_{\mathrm{r}}^{\frac{1}{3}}-\frac{\mathrm{V}_{\mathrm{r}}}{2}\right)}$

$\gamma_{\mathrm{e}}$ - the crosslink density $\left(\mathrm{mol} \mathrm{cm} \mathrm{cm}^{-3}\right), \mathrm{V}_{0}$ - solvent molar volume $\left(106.7 \mathrm{~cm}^{3} \mathrm{~mol}^{-1}\right), \mathrm{V}_{\mathrm{r}}$-volume fraction of rubber in a swollen sample, $\mu$-Flory-Huggins rubber-solvent interaction parameter. Natural rubber-toluene interaction factor $\mu_{0}$ and $\beta$ were experimentally $\left(\mu_{0}=0.478, \beta=0.228\right)$.

The tensile measurements were carried out on dumbbell-shaped specimens by using a universal testing machine (Zwick Company, model 1435, Germany) according to ISO37 at room temperature. The cross-head speed of testing was- $500 \mathrm{~mm} \mathrm{~min}^{-1}$. At least five different sample were tested from each rubber biocomposites.

The hardness of the rubber vulcanizates was tested according to ISO 868 standard by use Shore type A Durometer (Zwick Company, Germany). The result was calculated as the average of ten measurements taken from different areas of the sample.

Tear strength was determined using universal testing machine (Zwick Company, Germany) according to ISO 34 standard. The measurement was performed for "trousers" shape of the samples. Dimensions of the samples: length $100 \mathrm{~mm}$, width $15 \mathrm{~mm}$, and thickness $1 \mathrm{~mm}$ with a precut of $40 \mathrm{~mm}$ at the center. Three specimens were examined and the average value for each composites was reported.
DMA analysis were determined by means of DMA/ SDTA861e analyzer (Mettler Toledo). Test parameters: temperature range $-150-60{ }^{\circ} \mathrm{C}$, heating rate $-3{ }^{\circ} \mathrm{C} \mathrm{min}{ }^{-1}$, frequency $-1 \mathrm{~Hz}$, strain amplitude $-0.05 \%$.

The thermo-oxidative aging simulation process was carried out in thermo-circulation oven at $70{ }^{\circ} \mathrm{C}$ for 14 days. Then, mechanical properties of aged samples were tested. The ageing coefficient $(\mathrm{K})$ was determined as the numerical change in the static mechanical properties of the samples upon degradation process (Eq. 2):

$K=\left(T S \cdot E_{b}\right)_{\text {after aging }} /\left(T S \cdot E_{b}\right)_{\text {before aging }}$

where $\mathrm{E}_{\mathrm{b}}$-elongation at break, TS — tensile strength.

The relative damping coefficient of vulcanizes were measured at room temperature under the influence of compressive stress on a tensile testing machine (Zwick Company, Germany). Samples of vulcanizates (disc shape: diameter-35 mm, height-17.8 mm) were stressed from 0 to $0.7 \mathrm{MPa}$ and then stress was reduced by five times (five cycles). The relative damping coefficient was calculated based on recorded hysteresis loops according to the Eq. 3:

$T_{\tau w}=\frac{\Delta W_{i}}{\Delta W_{i b e l}} \cdot 100 \%$

where $\mathrm{T}_{\tau \mathrm{w}}$-relative damping, $\Delta \mathrm{W}_{\mathrm{i}}$ - the difference between the compression work and the work during reduc-

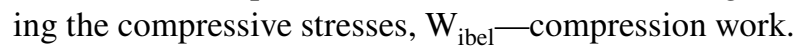

The polymer-filler and filler-filler interactions were estimated based on the Payne Effect, that values for the vulcanizates were calculated based on the Eq. 4.

$\Delta G^{\prime}=G_{\min }^{\prime}\left(\lim 10^{-1}\right)-G_{\max }^{\prime}(\infty)$

$\mathrm{G}_{\text {min }}^{\prime}\left(\lim 10^{-1}\right)$ - a composite storage modulus determined under the deformation of $0,1 \% ; \mathrm{G}_{\text {max }}^{\prime}(\infty)$ - a composite storage modulus determined under the max deformation. 
The test was carried out in the ARES Rheometer by the analysis of the strain scanning applied to the vulcanizates in the range between 0.1 and $100 \%$ and frequency of $50 \mathrm{~Hz}$ with sample deformation rate $10 \mathrm{rad} \mathrm{s}^{-1}$ and force: $5 \mathrm{~N}$ at $25{ }^{\circ} \mathrm{C}$.

The morphology of composites samples (10 phr of straw) and the dispersion of the filler were evaluated by means of Scanning Electron Microscopy with field emission Hitachi TM-1000 (Japan).

\section{Characteristic of the Fillers}

\section{Fourier Transform Infrared Spectroscopy Analysis}

The FTIR analysis for raw, pre-treated and modified straw were showed in Fig. 2 and Table 3. A broad band at $3600-3000 \mathrm{~cm}^{-1}$ (with a maximum at around $3300 \mathrm{~cm}^{-1}$ ) typical for the vibration of $-\mathrm{OH}$ groups was present in the spectra of all the materials tested. Another two peaks at around 2900 and $2850 \mathrm{~cm}^{-1}$ were related to asymmetric and symmetric methyl and methylene stretching groups. The characteristic bands at 890 and $1420 \mathrm{~cm}^{-1}$ were defined as the $\mathrm{C}-\mathrm{H}$ bending of amorphous and crystalline cellulose. Moreover, the peak at $1360 \mathrm{~cm}^{-1}$ was related to $\mathrm{C}-\mathrm{OH}$ stretching of the hydrogen bond intensity of crystalline cellulose. These absorption bands remained rather unchanged for all tested straws.

Alkali pre-treatment (see Fig. 2a) reduced hydrogen bonding due to removal of the hydroxyl groups by reacting with sodium hydroxide. This is indicated by the decrease of the peaks between 3000 and $3600 \mathrm{~cm}^{-1}$.

The peak at $1730 \mathrm{~cm}^{-1}$, which was related to the $\mathrm{C}=\mathrm{O}$ bond of the carboxylic group of hemicelluloses and pectin, was seen in the untreated samples but became weaker with the alkali treatment. The peak $1230 \mathrm{~cm}^{-1}$ that was assigned to $\mathrm{C}-\mathrm{O}$ and $\mathrm{C}=\mathrm{O}$ stretching in condensed guaiacyl units of
Fig. 2 FTIR spectra of a pure and pre-treated straw $\mathbf{b}$ modified straw
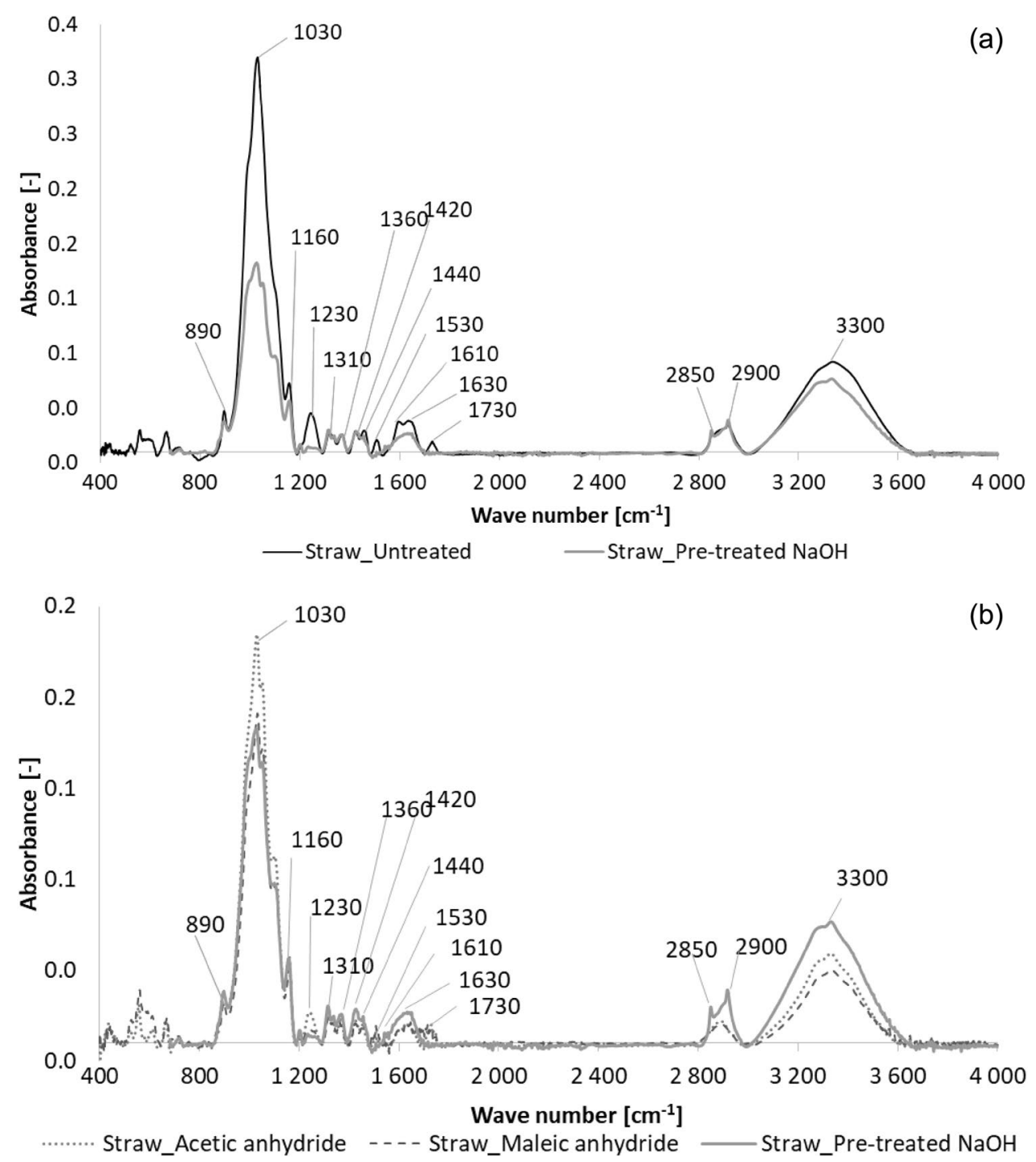
Table 3 Characteristic bands of the FT-IR spectra of the straw samples studied

\begin{tabular}{ll}
\hline Wave number $\mathrm{cm}^{-1}$ & Peak assignments \\
\hline $3500-3000$ & $\mathrm{O}-\mathrm{H}$ stretching \\
$2900-2800$ & $\mathrm{C}-\mathrm{H}_{\mathrm{n}}$ stretching \\
1730 & $\mathrm{C}=\mathrm{O}$ stretching \\
1630 & $\mathrm{O}-\mathrm{H}$ deformation, due to of $\mathrm{H}_{2} \mathrm{O}$ \\
1610 & $\mathrm{C}=\mathrm{C}$ aromatic skeletal vibration \\
1530 & $\mathrm{C}=\mathrm{C}$ aromatic skeletal vibration \\
1440 & $\mathrm{C}=\mathrm{C}$ aromatic skeletal vibration; $\mathrm{C}-\mathrm{H}$ deformation \\
1420 & $\mathrm{C}-\mathrm{H}$ deformation \\
1360 & $\mathrm{C}-\mathrm{H}$ and O-H bend \\
1310 & $\mathrm{CH}$ wag of celullose \\
1230 & $\mathrm{C}-\mathrm{O}$ stretching \\
1160 & $\mathrm{C}-\mathrm{O}-\mathrm{C}$ asymetric stretching \\
1030 & $\mathrm{C}-\mathrm{O}$ stretching \\
890 & Glucose ring stretching; $\mathrm{C}-\mathrm{H}$ out of plane deformation \\
\hline
\end{tabular}

lignin is well defined in the untreated fibers. Both peak at 1610 and $1530 \mathrm{~cm}^{-1}$ were due to $\mathrm{C}=\mathrm{C}$ stretching and $\mathrm{C}=\mathrm{C}$ aromatic skeletal vibration of lignin. These peaks were reduced in the spectra of the modified $(\mathrm{NaOH})$ samples. These phenomena are an indication of the removal of hemicellulose, pectin, and part of lignin from straw in alkaline solution.

Straw modified with anhydrides exhibited two distinct increase in absorbtion bands at 1730 and $1230 \mathrm{~cm}^{-1}$, respectively, which can be assigned to ester and $\mathrm{C}-\mathrm{O}$ bonds (see Fig. 2b). This was due to substantial acetyl and ester groups becoming attached to the straw fibers.

\section{Thermogravimetric Analysis}

The analysis of thermal decomposition of the natural filler was carried out in order to determine the temperature range in which the intense disintegration of components contained in individual samples occurs. Knowledge of the thermal distribution of the filler and the determination of the temperature at which the largest loss of mass is revealed, are helpful in determining the processing parameters of the finished product. The recorded TG and DTG curves and their characteristics are presented in Table 4 and Fig. 3.
The degradation profiles of the tested materials consist of two distinct stages. The loss of mass in the first step occurred in the range of $60-100{ }^{\circ} \mathrm{C}$ (peak at approx. $70{ }^{\circ} \mathrm{C}$ - see Fig. 3b) due to the evaporation of moisture from the fiber structure. The weight loss for the raw straw at $100{ }^{\circ} \mathrm{C}$ was ca. $6 \%$. The $\Delta \mathrm{m}_{100}$ value for the modified filler was reduced by approximately $2 \%$. The lower moisture content in the sample can be the result of increased hydrophobicity of the modified straw, which can positively affect the interface between the filler and the non-polar elastomer matrix.

In the next thermal decomposition step, the temperatures were concentrated in a wide range from 200 to $390{ }^{\circ} \mathrm{C}$, and the weight loss was due to the decomposition of the lignocellulosic material. Due to the high moisture content in the samples, the initial decomposition temperature of the tested fillers associated with the degradation of the lignocellulosic material was assumed to be the temperature in which a $1 \%$ weight loss occurred after $100{ }^{\circ} \mathrm{C}$ (the evaporation of the sample was caused by evaporation of water). Pure straw began to decompose at $199{ }^{\circ} \mathrm{C}$, while for straw modified with anhydrides an increase in the temperature of the beginning of degradation $\left(\mathrm{T}_{\mathrm{d}}\right)$ to 235 and $220^{\circ} \mathrm{C}$ was observed, respectively for straw modified with acetic anhydride and maleic anhydride.
Table 4 Thermal stability of fillers determined by TGA

\begin{tabular}{lllllll}
\hline & $\mathrm{T}_{\mathrm{d}}\left({ }^{\circ} \mathrm{C}\right)$ & $\mathrm{T}_{10}\left({ }^{\circ} \mathrm{C}\right)$ & $\mathrm{T}_{50}\left({ }^{\circ} \mathrm{C}\right)$ & $\Delta \mathrm{m}_{100}(\%)$ & $\Delta \mathrm{m}_{350}(\%)$ & $\begin{array}{l}\text { Rest at } \\
600{ }^{\circ} \mathrm{C} \\
(\%)\end{array}$ \\
\hline Straw_untreated & 199 & 246 & 332 & 6.08 & 64.35 & 20.82 \\
Straw_acetic anhydride & 235 & 290 & 358 & 4.19 & 38.68 & 14.53 \\
Straw_maleic anhydride & 220 & 269 & 352 & 4.21 & 46.88 & 16.83 \\
\hline
\end{tabular}

$\mathrm{T}_{\mathrm{d}}$-temperature of $1 \%$ mass loss of the sample after $100, \mathrm{~T}_{10}$-temperature of $10 \%$ mass loss, $\mathrm{T}_{50}$ temperature of $50 \%$ mass loss, $\Delta \mathrm{m}_{100}$-mass loss at $100{ }^{\circ} \mathrm{C}$ of the sample, $\Delta \mathrm{m}_{350}$-mass loss at $350{ }^{\circ} \mathrm{C}$ $\Delta \mathrm{m}_{100}$-mass loss in $100^{\circ} \mathrm{C}$, Rest at $600{ }^{\circ} \mathrm{C}$ - total mass loss at $600^{\circ} \mathrm{C}$ of the sample 
Fig. 3 a TG and b DTG curve of raw and modified straw
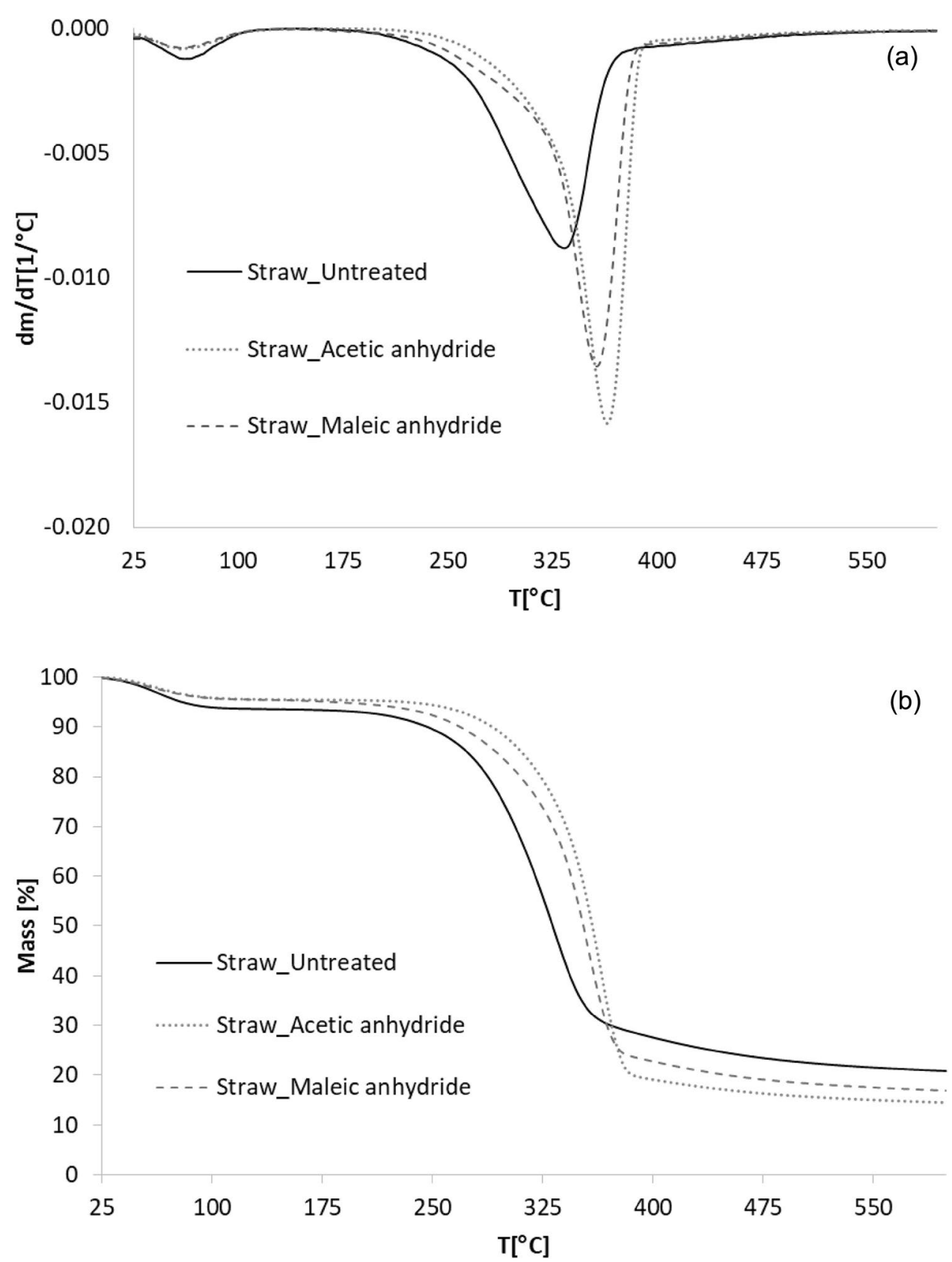

The basic biomass components undergo thermal decomposition at various temperatures. Studies on the thermal stability of natural fibers reveal that cellulose is completely degraded in a higher temperature range $\left(220-450{ }^{\circ} \mathrm{C}\right)$ than hemicellulose $\left(160-300{ }^{\circ} \mathrm{C}\right)$ and lignin $\left(160-400{ }^{\circ} \mathrm{C}\right)$ [40]. Differences in the degradation process of the tested straw samples therefore confirmed a different composition of the tested materials.

The anhydride solution improves the thermal stability of the biofillers. In addition, the raw straw decomposed faster than the modified straw, and this process corresponded to a much larger percentage loss in mass at lower temperatures (see Table 4). On DTG curves, the most intense peaks occurred at 330 and $350{ }^{\circ} \mathrm{C}$, respectively for the unmodified and the anhydride-treated filler. This shift may be due to a higher content of cellulose (characterized by greater thermal stability) in modified samples. Furthermore, the residue after the filler degradation was the highest for raw straw, which also corresponded with the reduction of lignin content in the modified straw. Among the constituents of lignocellulosic materials during pyrolysis, lignin has the highest proportion of solid residue [41]. 


\section{Characteristic of Composites}

\section{Rheological Properties of Rubber Mixtures and Crosslinking Density of Biocoposities}

The effect of the addition of lignocellulosic filler on the minimum and maximum torque, its increase during vulcanization and the course of rheometric curves are shown in Fig. 4. The scorch and vulcanization time of the elastomer blends was also determined (Fig. 5).

The introduction of straw into the elastomer matrix has shortened the optimum curing time of the blends compared to unfilled natural rubber. Only in the case of 20 and $30 \mathrm{phr}$ content of straw modified with maleic anhydride, the value of $t_{90}$ increased to values comparable with the reference sample. It may be the agglomeration effect of the filler particles at higher contents. The minimum torque has slightly changed, so the viscosity of rubber compounds also varied. However, in general, the effect of the presence of different types of fillers on the value of $\mathrm{M}_{\min }$ varied. The increase in the rheological moment of the blends, which is an indirect measure of the crosslinking density of the polymer, depends on the type and amount of filler. The data presented proved the activity of the natural particles, which created their own spatial network in the elastomer. In addition, the improvement of $\Delta \mathrm{M}$ was accompanied by an increase in filler content in the blends. It is worth noting that with the addition of $10 \mathrm{phr}$ modified fillers, an increase in the torque gain was observed in relation to the composite filled with raw straw. The modification influenced the activity of the filler surface and the reduction of its hydrophilicity and as a consequence contributes to better adhesion of the straw particles to the polymer matrix. The $\Delta \mathrm{M}$ reduction at higher straw contents may be the result of an increased agglomeration tendency for anhydride-modified fillers.

The use of fillers also affects the hydrodynamic effect, as a result of which the stresses generated in the elastomeric network are greater than those resulting from the applied deformation. Therefore, it seems likely that the increase in the rheological torque of the mixtures was caused by the increase in the density of the spatial network of vulcanizates (Fig. 6). The presence of the filler influenced the vulcanizates crosslinking density. According to the equilibrium swelling measurements, with the higher amount of straw used the increase in the density of vulcanizates was observed regardless of the type of filler. Moreover, in the case of composites filled with modified straw, the increase in $\nu_{\mathrm{e}}$ values occurred only at the content of $10 \mathrm{phr}$ filler compared to vulcanizates containing untreated straw. The treatment of the lignocellulosic material with anhydrides contributed to the ability to create its own spatial network in the polymer matrix. Equilibrium swelling tests reflect the results of rheological properties of rubber mixtures, where a similar tendency was observed.

\section{Mechanical Properties of Biocomposities}

The analysis of mechanical properties is presented in Table 5. The improvement of tensile strength of natural rubber composites was observed in the case of composites filled with 10 and $20 \mathrm{phr}$ of raw straw. A further increase in tensile strength was demonstrated by vulcanizates containing 10 phr of modified straw. Higher content of the processed filler resulted in a decrease in the TS value. An important factor that affects the mechanical properties is the good dispersion of the filler particles in the polymer matrix. Appropriate degree of dispersion allows for uniform distribution of forces and reduction of stress concentration, which leads to improvement of strength properties. In the case of increasing the content of the modified straw with anhydrides, the tensile strength decreased with increasing filler content, probably due to the agglomeration of the straw particles in the elastomer. Agglomerates acted as centers of stress concentration in the sample during stretching, causing a faster damage to the sample, which was confirmed by a decrease in the Eb value. This could be due to the increase in their surface activity and the susceptibility to filler-filler interactions. The reduction of the elongation at break of the composites was accompanied by an increase in the straw content regardless of its type.

\section{Thermooxidative Aging Process}

During storage, processing and exploitation polymer products are exposed to atmospheric factors. Due to the influence of external factors, there may be a change in the appearance and/or loss of desired properties, e.g. mechanical, usually as a result of degradation of the polymer resulting from a change in chemical structure (including oxidation or reduction of molecular weight). The rate of aging is increased by heat (thermal degradation). The type and intensity of changes in material properties during the exploitation of the manufactured product also depend on its structure and morphological defects (eg crystalline content, type of additives used).

In order to determine the effect of straw addition and its modification on the resistance of vulcanizates to aging, a simulation thermo-oxidative aging process was carried out (Fig. 7). Aging resistance was evaluated based on the change in mechanical properties in the static tensile test before and after aging. Exposure of composites to thermooxidative conditions resulted in increased stiffness and brittleness of vulcanizates. As a consequence, the tensile strength and the elongation at break decreased, as evidenced by the value of the coefficient $\mathrm{K}$ below one. The filled composites showed 
Fig. 4 Curing curves for natural rubber biocomposites filled with a 10 phr straw b 20 phr straw c $30 \mathrm{phr}$ straw
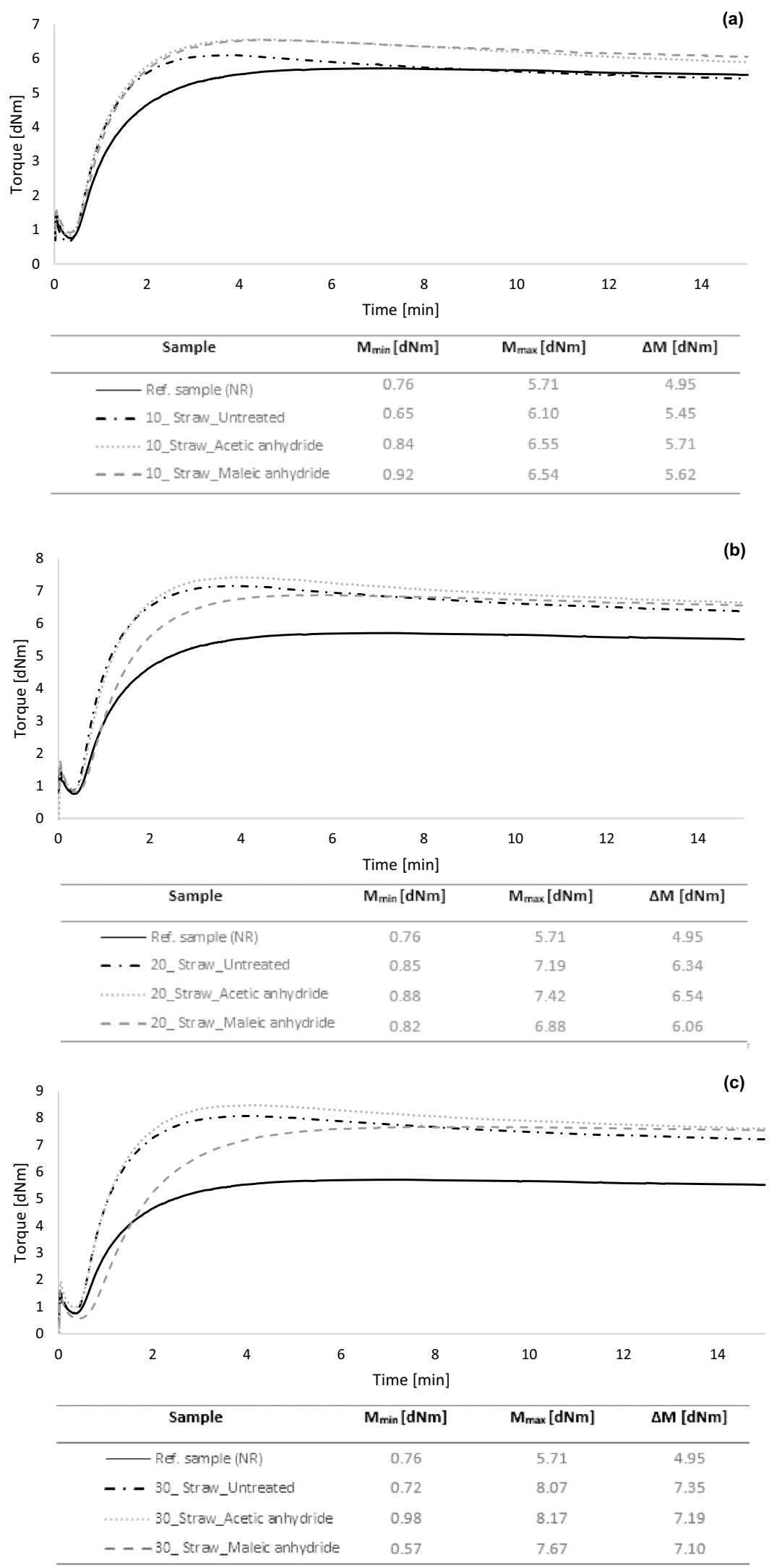
Fig. 5 Effect of straw content on scorch and optimum cure time on natural rubber composites
Fig. 6 Crosslinking density of NR vulcanizates filled with raw and modified straw
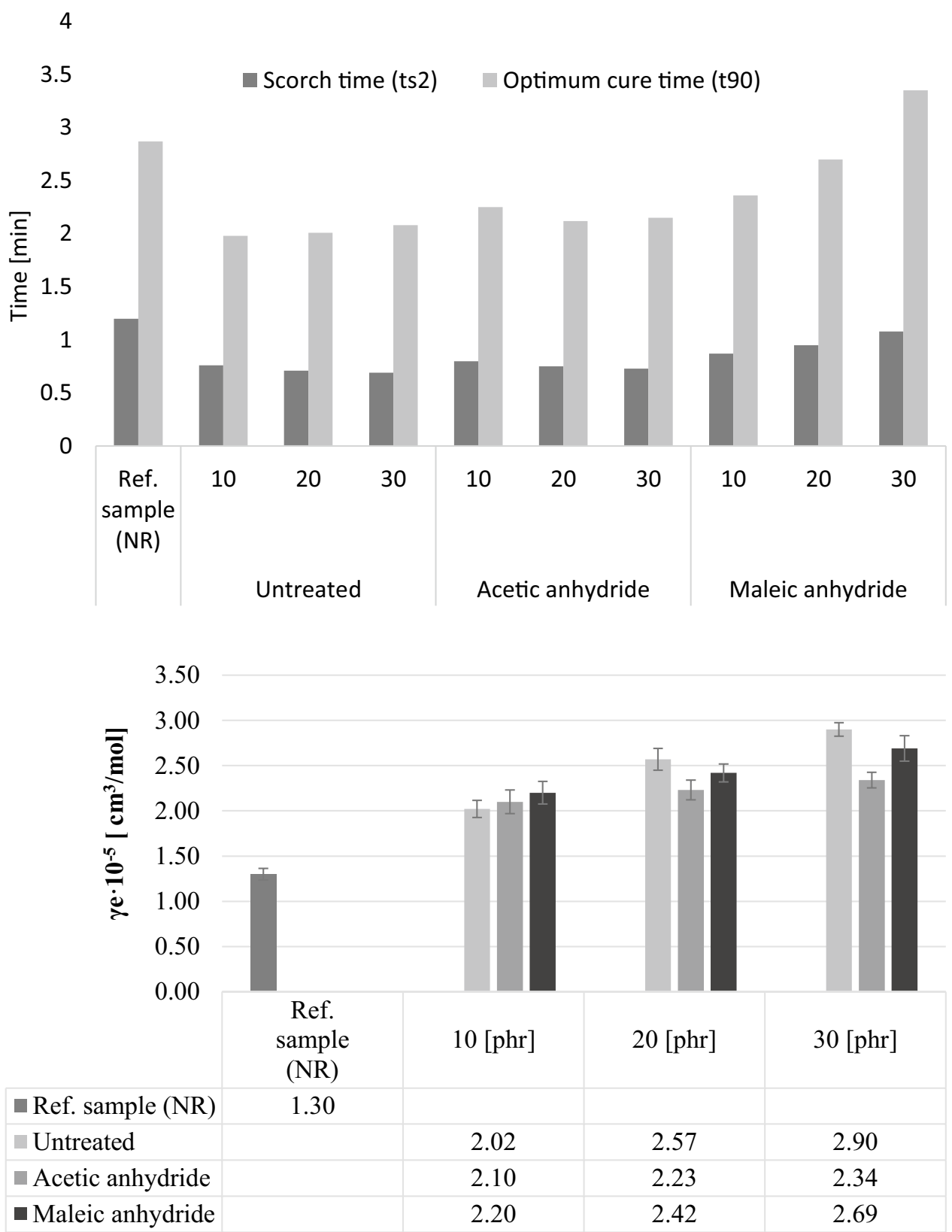

a higher aging rate compared to the reference sample. The coefficient $\mathrm{K}$ of vulcanizates with pure straw was about 0.7 . In addition, a slight improvement in the resistance to the degradation process was observed for composites filled with modified straw, for which the value of the coefficient $\mathrm{K}$ was even 0.95 .

\section{Tear Strength of Biocomposites}

Tear strength is important both during the processing of elastomeric composites (eg at the stage of removing the product from the mold) and during the exploitation of finished products. The use of raw straw as a filler of natural rubber adversely affected the tear strength. Regardless of the filler content, the $\mathrm{F}_{\text {mit }}$ value for vulcanizates with the addition of pure straw was lower compared to the unfilled system. The improvement of tearing resistance of composites was obtained by modifications of the filler, which contributed to the increase of interfacial interactions and positively influenced the strength characteristics of the material (Fig. 8).

\section{Damping Properties of Vulcanizates}

Susceptibility to vibration damping can be expressed as the ratio of dissipation energy to accumulated strain energy. Dissipation energy can be determined based on the 
Table 5 Mechanical properties and hardness of vulcanizates

\begin{tabular}{lccccc}
\hline & $\begin{array}{l}\text { Content of } \\
\text { straw }(\mathrm{phr})\end{array}$ & $\mathrm{SE}_{300}(\mathrm{MPa})$ & $\mathrm{TS}(\mathrm{MPa})$ & $\mathrm{Eb}(\%)$ & $\mathrm{H}\left({ }^{\circ} \mathrm{Sh} \mathrm{A}\right)$ \\
\hline Ref. sample (NR) & 0 & $1.84 \pm 0.05$ & $13.53 \pm 0.68$ & $585 \pm 15$ & $26.2 \pm 0.6$ \\
Untreated & 10 & $2.58 \pm 0.04$ & $15.3 \pm 0.71$ & $597 \pm 7$ & $34.3 \pm 0.9$ \\
& 20 & $3.65 \pm 0.16$ & $17.53 \pm 0.40$ & $567 \pm 17$ & $38.8 \pm 0.6$ \\
& 30 & $4.21 \pm 0.05$ & $14.28 \pm 0.22$ & $519 \pm 18$ & $45.3 \pm 07$ \\
Acetic anhydride & 10 & $2.58 \pm 0.14$ & $16.70 \pm 0.25$ & $608 \pm 8$ & $35.2 \pm 0.7$ \\
& 20 & $2.82 \pm 0.05$ & $13.57 \pm 0.31$ & $583 \pm 3$ & $39.3 \pm 0.3$ \\
Maleic anhydride & 10 & $3.57 \pm 0.13$ & $10.83 \pm 0.68$ & $511 \pm 10$ & $42.6 \pm 0.8$ \\
& 20 & $2.97 \pm 0.24$ & $17.30 \pm 0.75$ & $596 \pm 24$ & $35.1 \pm 0.5$ \\
& 30 & $3.63 \pm 0.17$ & $13.64 \pm 0.21$ & $545 \pm 16$ & $40.7 \pm 0.8$ \\
& $4.03 \pm 0.14$ & $9.72 \pm 0.35$ & $494 \pm 14$ & $45.4 \pm 0.9$ \\
\hline
\end{tabular}

$S E_{300}$ stress at $300 \%$ elongation, $T S$ tensile strength, $E b$ elongation at break, $H$ hardness
Fig. 7 Effect of thermooxidative aging process on the tensile strength and thermal aging factor of vulcanizates
Fig. 8 Effect of straw content on tear strength of biocomposites
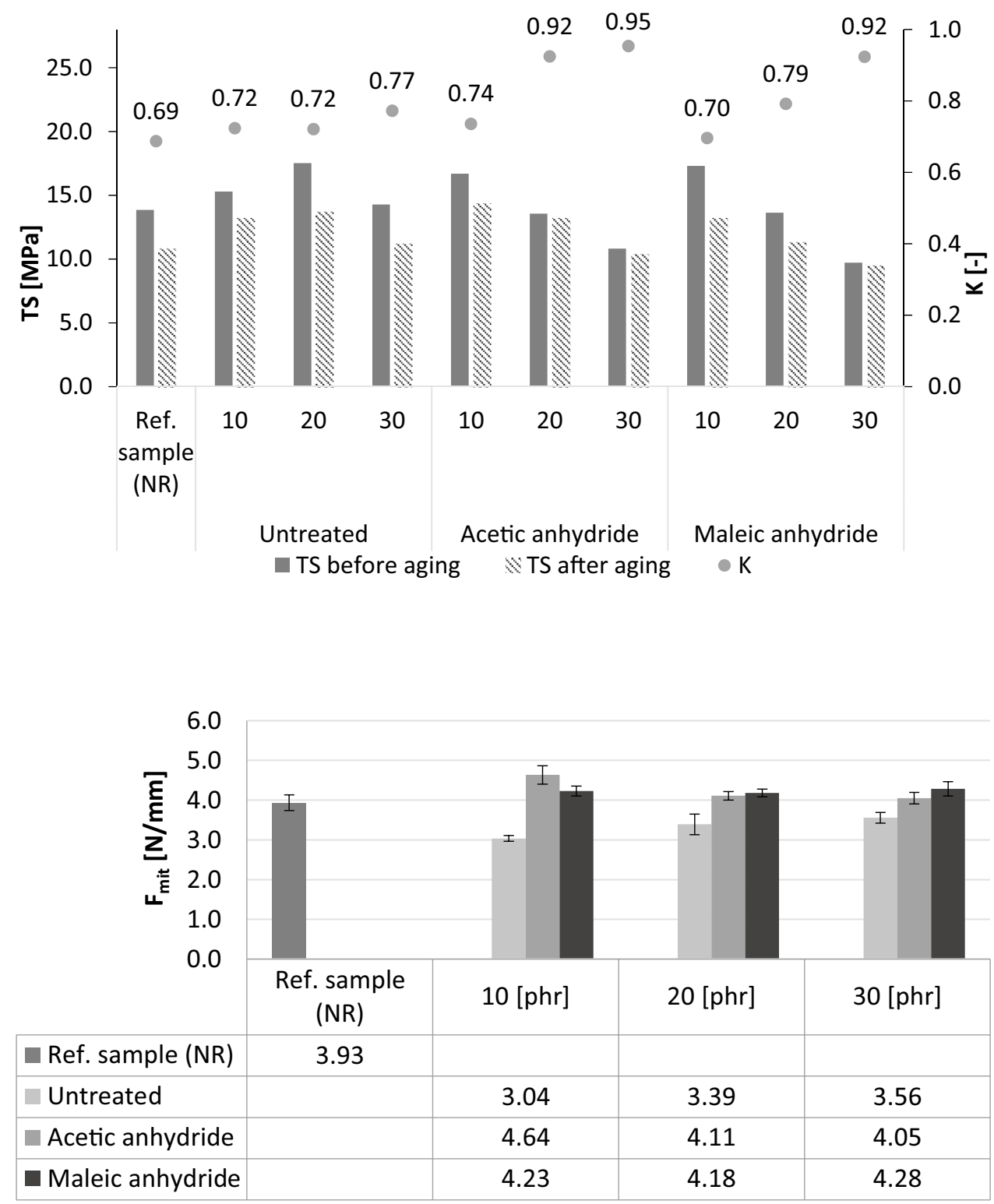
characteristics of the hysteresis loop during deformation. The surface of the obtained hysteresis loop illustrates the energy of deformation dispersed in one full cycle of deformation. It is the difference between the energy measured at the load and the energy obtained back when relieved. Understanding these relationships allow to evaluate the quality of processing, forecast long-term exploitation and strength characteristics, and the ability of materials to dissipate energy and suppress stress.

Natural rubber composites filled with raw and modified straw have a higher relative damping factor compared to an unfilled system (Fig. 9). An increasing trend of $T_{t w}$ values was also observed with an increase in the content of filler particles. The higher damping value was found in the case of composites with a modified filler, which is probably a manifestation of higher filler surface activity and good adhesion of the particles to the rubber compared to pure straw. A significant increase in damping ability for vulcanizates containing $30 \mathrm{phr}$ of modified straw may be due to the increased agglomeration tendency. Filling up to a large extent, the resulting clusters of particles can act as energy dissipating elements and improve the stress damping ability.

\section{Payne Effect of NR Vulcanizates}

Payne effect, i.e. the pronounced decrease of the storage modulus with increasing strain amplitude in filled rubbers under cyclic loading. Because the Payne effect does not occur in unfilled rubbers, its cause must be related to either the rubber-filler or the filler-filler interface [42]. The value of this effect is therefore influenced by the structure of the filler produced in the polymer matrix, which is destroyed during deformation and is manifested by a decrease in $\mathrm{G}^{\prime}$.
The degree of dispersion of the filler particles in the polymer is also significant.

The values of the Payne effect of composites containing a lignocellulosic filler are presented in Table 6 and Fig. 10. The modification of straw significantly influenced the activity of the filler, which resulted in an increase in $\Delta \mathrm{G}^{\prime}$. This indicates a significant ability to fill-filler and filler-polymer interactions. The greatest strengthening effect in static mechanical tests was obtained for composites containing $10 \mathrm{phr}$ filler (see Fig. 10). In addition, the results obtained herein confirmed that the most extensive secondary structure was achieved for composites containing modified straw. The increase content of anhydride-modified filler caused a decrease in the value of the Payne effect, probably due to the inhomogeneous distribution of the particles.

\section{Dynamic Mechanical Thermal Analysis}

The storage modulus $\left(\mathrm{E}^{\prime}\right)$ and loss modulus $\left(\mathrm{E}^{\prime \prime}\right)$ and the mechanical loss factor (tan delta), as a function of temperature $(\mathrm{T})$, were determined by dynamic mechanical analyzer were plotted versus temperature (Figs. 11, 12, 13).

Table 6 Payne effect of NR vulcanizates filled with $10 \mathrm{phr}$ straws

\begin{tabular}{lcll}
\hline $\begin{array}{l}\text { Content of } \\
\text { straw (phr) }\end{array}$ & $\Delta \mathrm{G}^{\prime}(\mathrm{MPa})$ & \\
\cline { 2 - 4 } & Untreated & Acetic anhydride & Maleic anhydride \\
\hline 10 & 58.2 & 174.9 & 297.8 \\
20 & 89.9 & 169.3 & 198.7 \\
30 & 110.0 & 116.7 & 184.5 \\
\hline
\end{tabular}

$\Delta G^{\prime}$ Payne effect
Fig. 9 The influence of straw filler type and content on relative damping

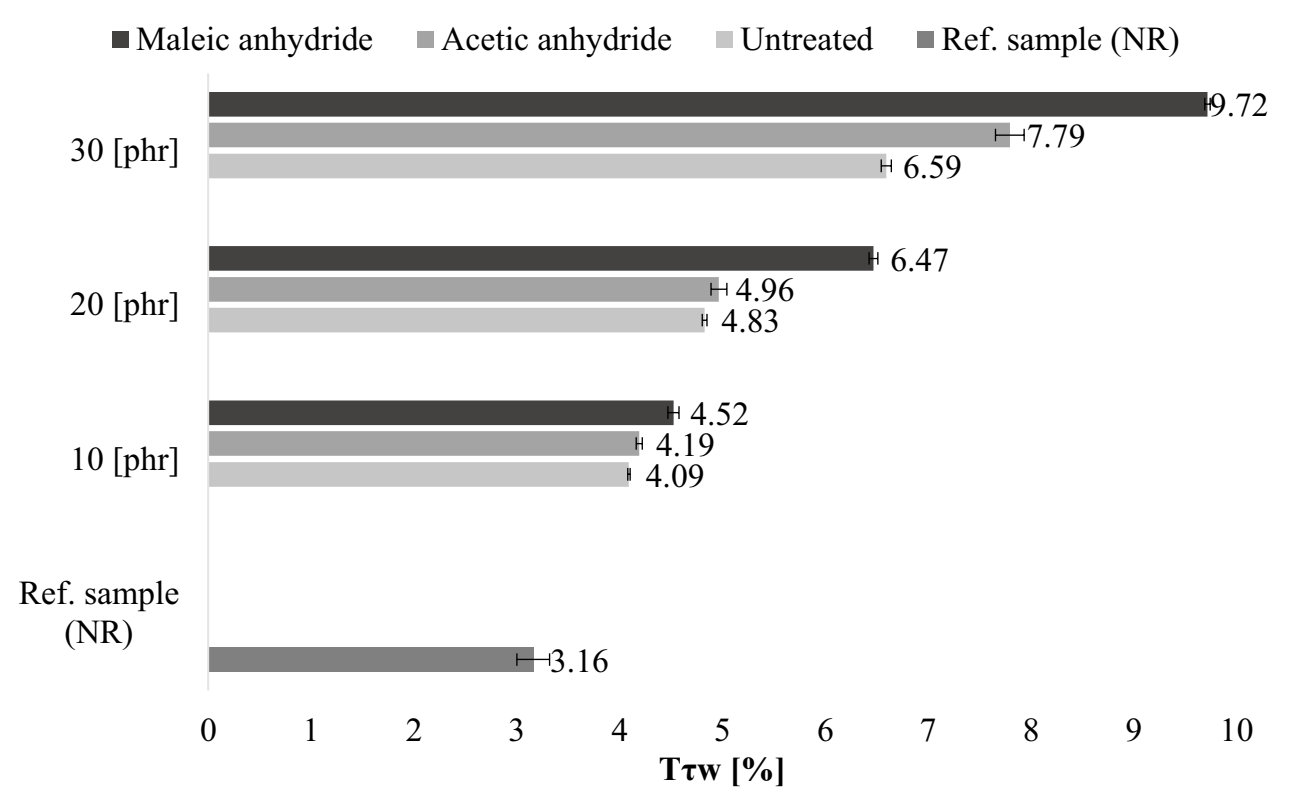


Fig. 10 Storage modulus-strain curves of prepared natural rubber composites reinforced with $10 \mathrm{phr}$ straws

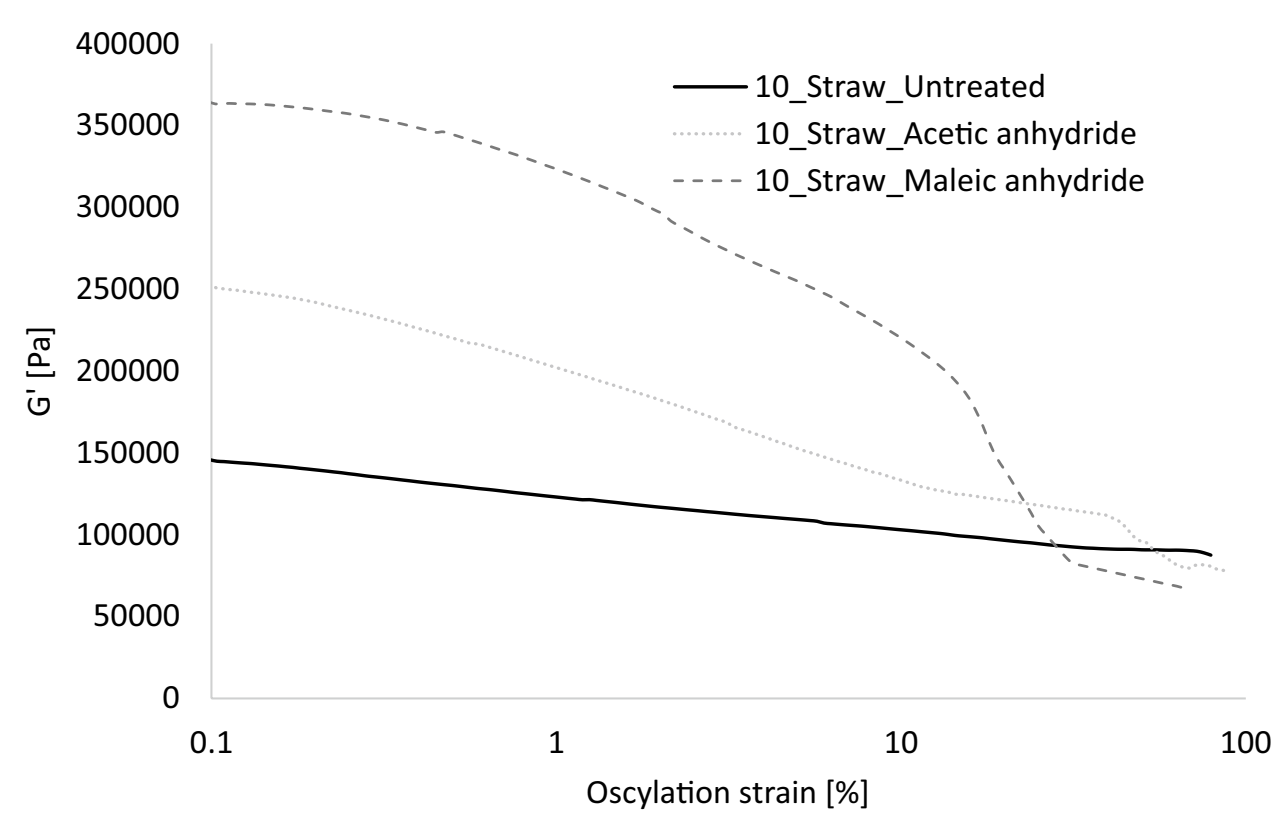

Fig. 11 Plot of storage modulus of vulcanizates (reference sample and composites filled with $10 \mathrm{phr}$ straw) as a function of temperature

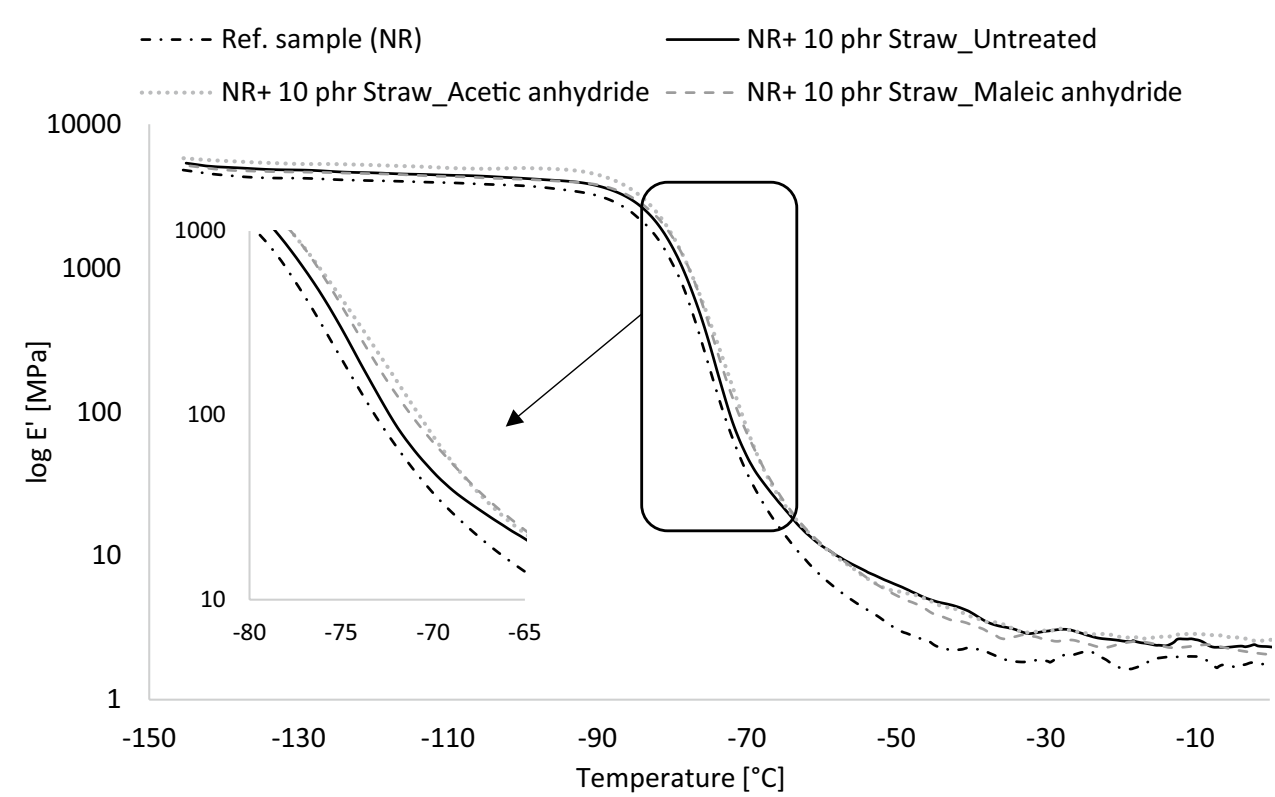

The observed increase in the storage module of filled composites in glass temperature region (ca. $-70{ }^{\circ} \mathrm{C}$ ) was the result of straw fibers addition (reinforcing effect) and as a result increased stiffness of the material. Moreover, in the case of composites containing a modified filler, an increase in the $E^{\prime}$ value was also observed. This could be related to a stronger rubber-filler interactions and higher elasticity modulus of treated straw fiber in comparison to raw straw.

The loss modulus $\left(\mathrm{E}^{\prime \prime}\right)$ is a measure of heat dissipated energy in one cycle of deformation, so-called viscous reaction of the material. Analysis of the data contained in Fig. 12 showed the widening of the loss module peak for filled composites. In addition, in the case of modified fibers, the
$\mathrm{E}^{\prime \prime}$ curve spreads even more widely. This is most likely the result of limiting the relaxation process due to inhibition of segmental motility of macromolecules. The introduction of straw increases the stiffness of polymer chains, further increases the heterogeneity of the material. The loss module in the transition area is also higher for composites containing MAA and AAS. It may be the result of a more developed filler structure, which contributed to the increase of internal friction forces, conducive to energy dissipation.

The height and position of the $\tan \delta$ peak determine the properties and structure of the polymer composite. The parameters exerting a major influence on the $\tan \delta$ value are the fiber distribution, the concentration of applied stresses, 
Fig. 12 Plot of loss modulus of vulcanizates (reference sample and composites filled with $10 \mathrm{phr}$ straw) as a function of temperature
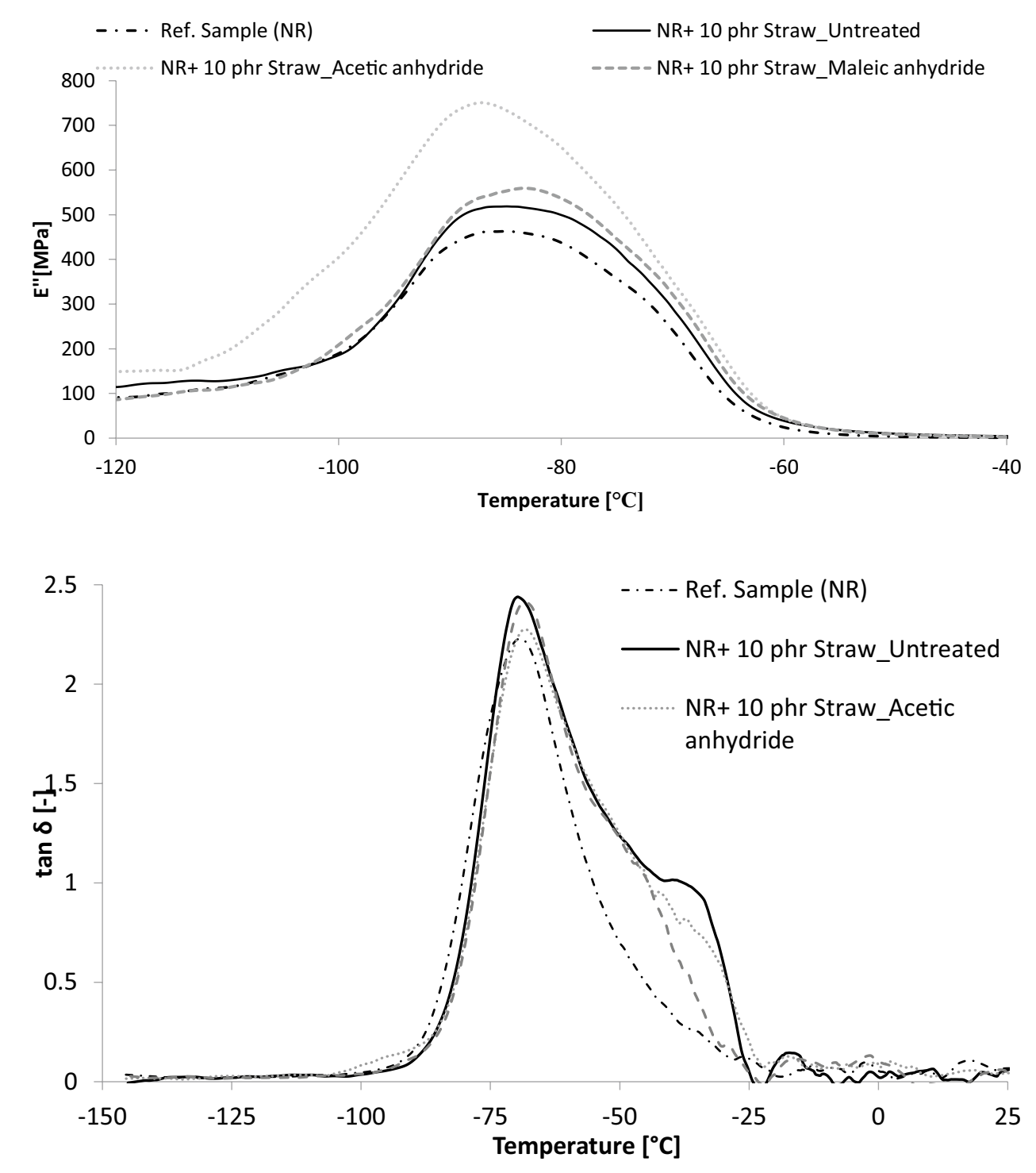

Fig. 13 Plot of tan $\delta$ of vulcanizates (reference sample and composites filled with $10 \mathrm{phr}$ straw) as a function of temperature the viscoelastic energy dissipation, as well as the effect of the filler on the polymeric medium. Energy dissipation will occur in the polymer matrix at the interface and a stronger interface allows less dissipation. This may be due to the limitation of the movement of polymer macromolecules due to the introduction of a rigid solid phase. The height of the tan $\delta$ peak can be indirectly a measure of reducing the molecular mobility of the elastomeric chains around the surface of the fiber, which allows to determine the degree of interfacial adhesion between the filler and the polymer. The numerical measure of elastomer-filler interactions is the factor A, expressed by the Eq. 5 [43]:

$A=\left(\frac{1}{1-V_{f}}\right) \times\left(\frac{\tan \delta_{c}}{\tan \delta_{r}}\right)-1$

where $V_{f}$ was the volume fraction of the fiber $(0.1)$, $\tan \delta_{c}$ was maximum tan $\delta$ peak of the NR biocomposites and tan $\delta_{\mathrm{r}}$ was maximum tan $\delta$ peak of the unfilled NR (reference sample).

The weaker impact of the unmodified filler with rubber showed a higher value of the adhesion coefficient. While the lower A values obtained for the composites containing AAS and MAS indicated good interfacial adhesion due to reduced mobility of the polymer chain, through a stronger interface between the components.

The glass transition temperature $(\mathrm{Tg})$ was determined on the basis of measurements of $\tan \delta$ values as a function of temperature, range from -150 to $25{ }^{\circ} \mathrm{C}$ (temperature at which $\tan \delta$ reached the maximum value). The presence of the filler caused a decrease in the segmental mobility of the polymer macromolecules, which resulted in an increase in the glass transition temperature (Table 7). The highest $\mathrm{Tg}$ values were obtained for composites containing modified straw, which may be due to the good interaction of the elastomer and filler surface. 
Table 7 Glass transition temperatures, maximum values of $\tan \delta$ and adhesion factors of NR composites

\begin{tabular}{llllc}
\hline & Ref. sample (NR) & $\begin{array}{l}\text { NR+10 phr } \\
\text { untreated straw }\end{array}$ & $\begin{array}{l}\text { NR+10 phr straw_ } \\
\text { acetic anhydride }\end{array}$ & $\begin{array}{l}\text { NR+10 phr } \\
\text { straw_maleic } \\
\text { anhydride }\end{array}$ \\
\hline $\begin{array}{c}\text { Tg (with respect to } \\
\tan \delta \max )\left({ }^{\circ} \mathrm{C}\right)\end{array}$ & -69.4 & -69.2 & -68.3 & -68.3 \\
$\tan \delta_{\max }$ & 2.23 & 2.44 & 2.28 & 2.41 \\
$\mathrm{~A}[-]$ & - & -0.01 & -0.08 & -0.03 \\
\hline
\end{tabular}

\section{Scanning Electron Microscopy}

Obtained SEM images of NR/straw (10 phr) systems (Fig. 14) showed a relatively good distribution of filler particles with visible aggregate and agglomerate structures for unmodified straw. Presented agglomerates (Fig. 14a) are in size of several tens of $\mu \mathrm{m}$. The appearance of isolated modified filler structures in the polymer matrix suggests that the particles have a greater affinity for fillerpolymer interactions than the filler-filler. This ensures a larger contact surface at the interface between two phases, resulting in better stress transfer. The improved dispersion of the treated straw particles in the elastomeric matrix provides a more efficient entrainment of the filler particles by the polymer, resulting in better adhesion between the phases in the composite. As a consequence, the dispersion and morphological properties of systems with modified fillers are relatively better. Observations confirmed previously obtained results of mechanical properties and crosslinking density of the vulcanizates.

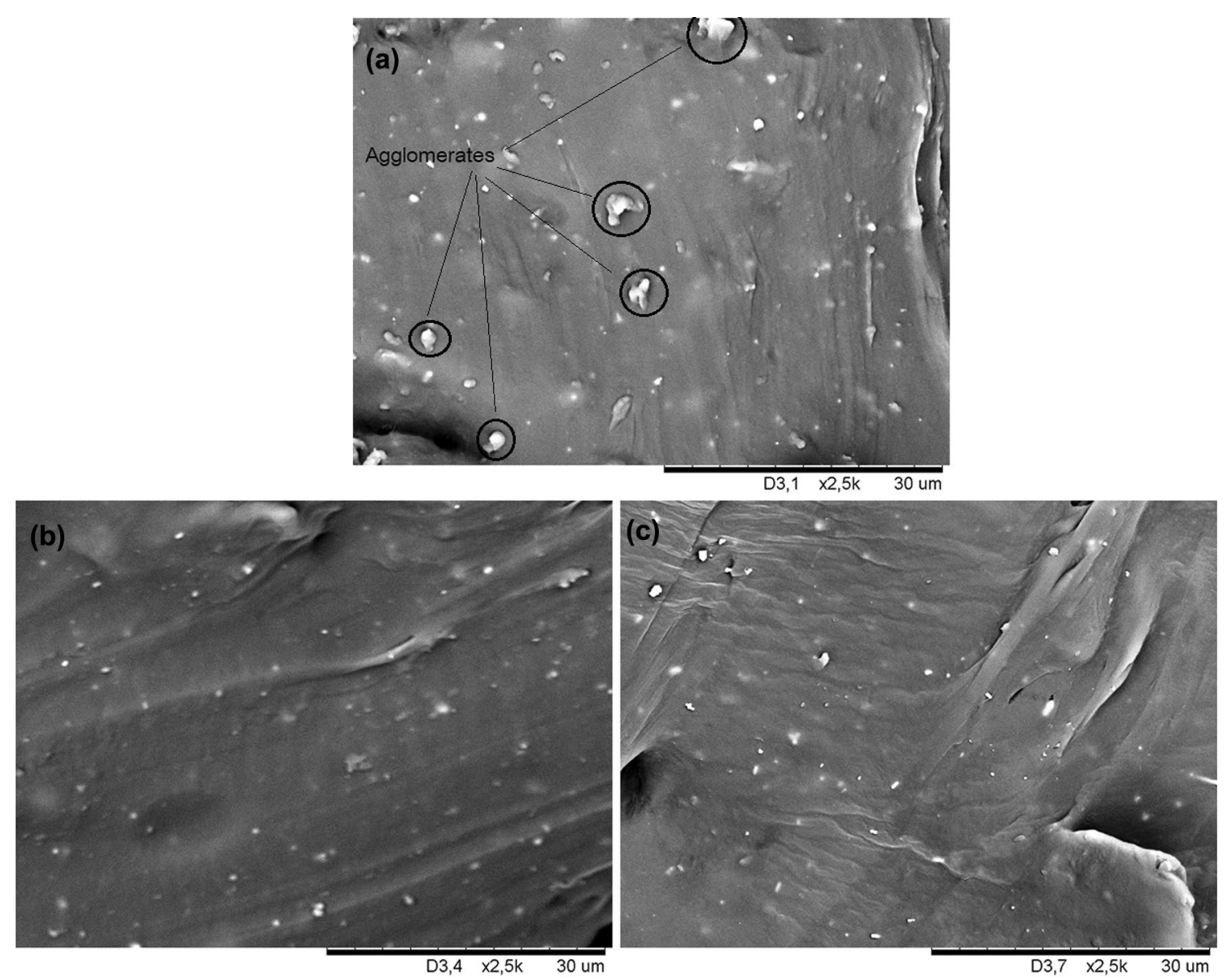

Fig. 14 SEM images of composities : a NR/pure straw (10 phr), b NR/acetic anhydride modified straw (10 phr) c NR/maleic anhydride modified straw (10 phr) 


\section{Conclusions}

The applied modifications significantly influenced the structure and properties of straw. The pre-alkalization allowed the removal of non-cellulosic substances and the exposure of the fibril surface, providing better wettability and fiber recyclability. The conducted chemical modifications influenced the presence of waxes, hemicellulose and lignin on the surface of straw. This also resulted in higher thermal stability of the tested materials, as non-cellulosic compounds undergo thermal degradation earlier than pure cellulose.

The applied modifications of straw used as a natural rubber filler ensured better adhesion at the interface between straw and elastomer in the produced composite material. Dynamic mechanical analysis showed an increase in the value of the Payne effect for composites containing straw modified with anhydrides, which indicates a more developed structure of treated fillers in the elastomer. In contrast, the improved adhesion between the straw particles modified with acetic and maleic anhydride has been confirmed by DMTA analysis. The increase in filler-filler and filler-polymer interactions caused an increase in the spatial elastomer network density, resulting in a more efficient transfer of stresses between the polymer matrix and the fiber, which consequently improved mechanical, damping and tensile properties. In addition, biocomposites filled with all types of straw showed improved resistance to thermo-oxidative aging compared to unfilled vulcanizates.

The filling degree is of key importance in composites filled with natural materials. The high filler activity due to its chemical modification also contributed to the increased tendency to agglomerate with higher straw contents.

One of the directions of development of polymeric materials is the preparation of composites containing available and cheap natural materials acting as a filler. A polymer composite in which at least one of the components is bio-based or biodegradable is referred to as a biocomposite. The main benefits resulting from the use of biocomposites as alternative materials for "oil-derived" products include preventing the imbalance in the demand and supply of products produced from non-renewable fossil raw materials, sustainable waste management, reduction of carbon dioxide emissions, biodegradability of materials or facilitated recycling process. Nevertheless, natural rubber/straw biocomposites have high application potential due to their multifunctional properties. These types of polymer composites are prospective consumables that provide economic, economic, ecological benefits.

Rubber products made from the composition, showing improved performance may be used, among others, as: damping mats, floor coverings, insulating materials, damping composites or all kinds of seals. Potential areas of application may be: construction, automotive, electric and electrotechnical, machine, household appliances or many more.

\section{Compliance with Ethical Standards}

Conflict of interest The authors declare that they have no conflicts of interest.

Open Access This article is distributed under the terms of the Creative Commons Attribution 4.0 International License (http://creativeco mmons.org/licenses/by/4.0/), which permits unrestricted use, distribution, and reproduction in any medium, provided you give appropriate credit to the original author(s) and the source, provide a link to the Creative Commons license, and indicate if changes were made.

\section{References}

1. Kaczmar JW, Pach J, Burgstaller C (2011) The chemically treated hemp fibres to reinforce polymers. Polimery/Polymers $56: 817-822$

2. John MJ, Anandjiwala RD (2008) Recent developments in chemical modification and characterization of natural fiber-reinforced composites. Polym Compos 29:187-207

3. Pickering KL, Efendy MGA, Le TM (2016) A review of recent developments in natural fibre composites and their mechanical performance. Compos Part A: Appl Sci Manuf 83:98-112. https ://doi.org/10.1016/j.compositesa.2015.08.038

4. Jonoobi M, Harun J, Mathew AP et al (2010) Preparation of cellulose nanofibers with hydrophobic surface characteristics. Cellulose 17:299-307. https://doi.org/10.1007/s10570-009-9387-9

5. Chen P, Lu C, Yu Q et al (2006) Influence of fiber wettability on the interfacial adhesion of continuous fiber-reinforced PPESK composite. J Appl Polym Sci 102:2544-2551. https:// doi.org/10.1002/app.24681

6. Wu XF, Dzenis YA (2006) Droplet on a fiber: geometrical shape and contact angle. Acta Mech 185:215-225. https://doi. org/10.1007/s00707-006-0349-0

7. $\mathrm{Ke} \mathrm{G}, \mathrm{Yu} \mathrm{W}, \mathrm{Xu} \mathrm{W}$ et al (2008) Effects of corona discharge treatment on the surface properties of wool fabrics. J Mater Process Technol 207:125-129. https://doi.org/10.1016/j.jmatprotec .2007.12.068

8. Sakata I, Morita M, Tsuruta N, Morita K (1993) Activation of wood surface by corona treatment to improve adhesive bonding. J Appl Polym Sci 49:1251-1258. https://doi.org/10.1002/ app.1993.070490714

9. Wang Q, Kaliaguine S, Ait-Kadi A (1993) Catalytic grafting: a new technique for polymer-fiber composites. III. Polyethyleneplasma-treated KevlarTMfibers composites: analysis of the fiber surface. J Appl Polym Sci 48:121-136. https://doi.org/10.1002/ app.1993.070480113

10. Li X, Tabil LG, Oguocha IN, Panigrahi S (2008) Thermal diffusivity, thermal conductivity, and specific heat of flax fiber-HDPE biocomposites at processing temperatures. Compos Sci Technol 68:1753-1758. https://doi.org/10.1016/j.compscitech.2008.02.016

11. Faruk O, Bledzki AK, Fink H-P, Sain M (2014) Progress report on natural fiber reinforced composites. Macromol Mater Eng 299:9-26. https://doi.org/10.1002/mame.201300008 
12. Singh B, Gupta M, Verma A (1996) Influence of fiber surface treatment on the properties of sisal-polyester composites. Polym Compos 17:910-918. https://doi.org/10.1002/pc.10684

13. Yuan H, Nishiyama Y, Kuga S (2005) Surface esterification of cellulose by vapor-phase treatment with trifluoroacetic anhydride. Cellulose 12:543-549. https://doi.org/10.1007/s 1057 0-005-7136-2

14. Freire CSR, Silvestre AJD, Neto CP et al (2006) Controlled heterogeneous modification of cellulose fibers with fatty acids: effect of reaction conditions on the extent of esterification and fiber properties. J Appl Polym Sci 100:1093-1102. https://doi.org/10.1002/ app. 23454

15. Lu J, Askeland P, Drzal LT (2008) Surface modification of microfibrillated cellulose for epoxy composite applications. Polymer 49:1285-1296. https://doi.org/10.1016/j.polymer.2008.01.028

16. Li X, Tabil LG, Panigrahi S (2007) Chemical treatments of natural fiber for use in natural fiber-reinforced composites: a review. J Polym Environ 15:25-33. https://doi.org/10.1007/s1092 4-006-0042-3

17. Zhu J, Zhu H, Njuguna J, Abhyankar H (2013) Recent development of flax fibres and their reinforced composites based on different polymeric matrices. Materials (Basel) 6:5171-5198. https ://doi.org/10.3390/ma6115171

18. Bledzki AK, Fink HP, Specht K (2004) Unidirectional hemp and flax EP- and PP-composites: influence of defined fiber treatments. J Appl Polym Sci 93:2150-2156. https://doi.org/10.1002/ app.20712

19. Bera M, Alagirusamy R, Das A (2010) A study on interfacial properties of jute-PP composites. J Reinf Plast Compos 29:31553161. https://doi.org/10.1177/0731684410369723

20. Kabir MM, Wang H, Lau KT et al (2012) Mechanical properties of chemically-treated hemp fibre reinforced sandwich composites. Compos Part B Eng 43:159-169. https://doi.org/10.1016/j.compo sitesb.2011.06.003

21. Gomes A, Matsuo T, Goda K, Ohgi J (2007) Development and effect of alkali treatment on tensile properties of curaua fiber green composites. Compos Part A Appl Sci Manuf 38:1811-1820. https://doi.org/10.1016/j.compositesa.2007.04.010

22. Ibrahim NA, Hadithon KA, Abdan K (2010) Effect of fiber treatment on mechanical properties of kenaf fiber-ecoflex composites. $\mathrm{J}$ Reinf Plast Compos 29:2192-2198. https://doi.org/10.1177/07316 84409347592

23. Goda K, Sreekala MS, Gomes A et al (2006) Improvement of plant based natural fibers for toughening green composites-effect of load application during mercerization of ramie fibers. Compos Part A Appl Sci Manuf 37:2213-2220. https://doi.org/10.1016/j. compositesa.2005.12.014

24. Islam MS, Pickering KL, Foreman NJ (2010) Influence of alkali treatment on the interfacial and physico-mechanical properties of industrial hemp fibre reinforced polylactic acid composites. Compos Part A Appl Sci Manuf 41:596-603. https://doi.org/10.1016/j. compositesa.2010.01.006

25. Bledzki AK, Mamun AA, Lucka-Gabor M, Gutowski VS (2008) The effects of acetylation on properties of flax fibre and its polypropylene composites. Express Polym Lett 2:413-422. https://doi. org/10.3144/expresspolymlett.2008.50

26. Sparnins E (2006) Mechanical properties of flax fibers and their composites. CampuscornerFibre2FashionCom

27. Bledzki AK, Gassan J (1999) Composites reinforced with cellulose based fibres. Prog Polym Sci 24:221-274. https://doi. org/10.1016/S0079-6700(98)00018-5
28. Zafeiropoulos NE, Baillie CA, Hodgkinson JM (2002) Engineering and characterisation of the interface in flax fibre/polypropylene composite materials. Part II. The effect of surface treatments on the interface. Compos Part A Appl Sci Manuf 33:1185-1190. https://doi.org/10.1016/S1359-835X(02)00088-X

29. Manikandan Nair KC, Thomas S, Groeninckx G (2001) Thermal and dynamic mechanical analysis of polystyrene composites reinforced with short sisal fibres. Compos Sci Technol 61:2519-2529. https://doi.org/10.1016/S0266-3538(01)00170-1

30. Abdul Khalil HPS, Ismail H (2000) Effect of acetylation and coupling agent treatments upon biological degradation of plant fibre reinforced polyester composites. Polym Test 20:65-75. https://doi. org/10.1016/S0142-9418(99)00080-X

31. Franco-Marquès E, Méndez JA, Pèlach MA et al (2011) Influence of coupling agents in the preparation of polypropylene composites reinforced with recycled fibers. Chem Eng J 166:1170-1178. https ://doi.org/10.1016/j.cej.2010.12.031

32. Keener TJ, Stuart RK, Brown TK (2004) Maleated coupling agents for natural fibre composites. Compos Part A: Appl Sci Manuf. 35:357-362

33. Van de Velde K, Kiekens P (2003) Effect of material and process parameters on the mechanical properties of unidirectional and multidirectional flax/polypropylene composites. Compos Struct 62:443-448. https://doi.org/10.1016/j.compstruct.2003.09.018

34. Cantero G, Arbelaiz A, Llano-Ponte R, Mondragon I (2003) Effects of fibre treatment on wettability and mechanical behaviour of flax/polypropylene composites. Compos Sci Technol 63:12471254. https://doi.org/10.1016/S0266-3538(03)00094-0

35. Masłowski M, Miedzianowska J, Strzelec K (2017) Natural rubber biocomposites containing corn, barley and wheat straw. Polym Test 63:84-91. https://doi.org/10.1016/j.polymertes ting.2017.08.003

36. Masłowski M, Miedzianowska J, Strakowska A et al (2018) The use of rye, oat and triticale straw as fillers of natural rubber composites. Polym. Bull. https://doi.org/10.1007/s00289-018-2289-y

37. Rybiński P, Syrek B, Masłowski M et al (2017) Influence of lignocellulose fillers on properties natural rubber composites. J Polym Environ. https://doi.org/10.1007/s10924-017-1144-9

38. Bodîrlău R, Teacă CA (2009) Fourier transform infrared spectroscopy and thermal analysis of lignocellulose fillers treated with organic anhydrides. Rom Rep Phys 54:93-104

39. Flory PJ, Rehner J (1943) Statistical mechanics of cross-linked polymer networks I. Rubberlike ELASTICITY. J Chem Phys 11:512-520. https://doi.org/10.1063/1.1723791

40. Fan M, Naughton A (2016) Mechanisms of thermal decomposition of natural fibre composites. Compos Part B Eng 88:1-10. https://doi.org/10.1016/j.compositesb.2015.10.038

41. Yang H, Yan R, Chen H et al (2007) Characteristics of hemicellulose, cellulose and lignin pyrolysis. Fuel 86:1781-1788. https ://doi.org/10.1016/j.fuel.2006.12.013

42. Hentschke R (2017) The payne effect revisited. Express Polym Lett 11:278-292. https://doi.org/10.3144/expresspolymlet t. 2017.28

43. Formela K, Hejna A, Piszczyk $€$ et al (2016) Processing and structure-property relationships of natural rubber/wheat bran biocomposites. Cellulose 23:3157-3175. https://doi.org/10.1007/s 1057 0-016-1020-0 